\title{
2011/15
}

Vertical integration and exclusivities in maritime freight transport

Pedro Cantos-Sánchez, Rafael Moner-Colonques, José J. Sempere-Monerris and Óscar Álvarez-SanJaime

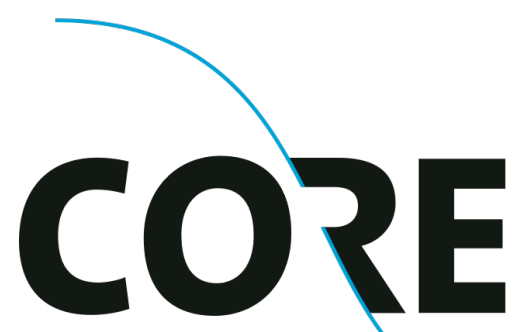

DISCUSSION PAPER

Center for Operations Research and Econometrics

Voie du Roman Pays, 34 B-1348 Louvain-la-Neuve Belgium http://www.uclouvain.be/core 


\title{
CORE DISCUSSION PAPER
}

$2011 / 15$

\section{Vertical integration and exclusivities in maritime freight transport}

\author{
Pedro CANTOS-SÁNCHEZ1 ${ }^{1}$, Rafael MONER-COLONQUES ${ }^{2}$, \\ José J. SEMPERE-MONERRIS ${ }^{3}$ and Óscar ÁLVAREZ-SANJAIME ${ }^{4}$
}

March 2011

\begin{abstract}
A key recent theme in maritime freight transport is the involvement of shipping lines in terminal management. Such investments are costly but allow liners to provide better service. Most of these new terminals are dedicated terminals but some are non-exclusive and let rivals access them for a fee. In this paper, we show that a shipping line that builds its own terminal finds it strategically profitable i) to continue routing part of its cargo through the open port facilities, and ii) to keep its terminal non-exclusive. In this way, the liner investor pushes part of the rival's freight from the open to the new terminal. Besides, under non-exclusivities, the shipping lines offer a wider variety of services, total freight increases and the resulting equilibrium fares are higher than with a dedicated terminal.
\end{abstract}

Keywords: freight transport, shipping lines, vertical integration.

JEL Classification: L13, L91, R40

\footnotetext{
${ }^{1}$ Department of Economic Analysis and ERI-CES, University of Valencia, Spain. E-mail: pedro.cantos@uv.es ${ }^{2}$ Department of Economic Analysis and ERI-CES, University of Valencia, Spain. E-mail: Rafael.moner@uv.es ${ }^{3}$ Department of Economic Analysis and ERI-CES, University of Valencia, Spain and Université catholique de Louvain, CORE, B-1348 Louvain-la-Neuve, Belgium.E-mail: jose.sempere@uv.es

${ }^{4}$ Department of Economic Analysis and IEI, University of Valencia, Spain. E-mail: oscar.alvarez@uv.es

The authors would like to thank participants at the Kuhmo Nectar Conference in Transport Economics (Valencia 2010) for their comments and suggestions. We gratefully acknowledge financial support from the Spanish Ministry of Science and Innovation and FEDER under projects ECO2010-20584 and ECO20101733, and Generalitat Valenciana under project PROMETEO/2009/068.

This paper presents research results of the Belgian Program on Interuniversity Poles of Attraction initiated by the Belgian State, Prime Minister's Office, Science Policy Programming. The scientific responsibility is assumed by the authors.
} 


\section{Introduction}

Over the last decades the liner shipping market has witnessed extensive changes both in sea transport and the stevedoring market. The move towards increasingly converging and integrating markets has produced a substantial growth in the scope of activities performed by carriers, in terms of geographic coverage, frequency of services, faster transit time and supply chain management. An increase in the complexity of the maritime logistics chain has indeed occurred. The usual competition between individual shipping companies and between ports has changed to competition between logistics chains (Suykens and Van de Voorde, 1998), basically composed of three large sections: the purely maritime services, the freight handling in the port and the hinterland services. An improved organization of these sections becomes fundamental regarding what "product" is offered by a shipping line at a particular port. A key recent theme is the involvement of shipping companies in terminal management. The objective of our paper is to analyze the derived effects of vertical integration between maritime services and terminal port activities on prices, demand and profits; we wish to assess whether it is strategically profitable for a shipping line to have a dedicated terminal and/or continue to employ the port's open infrastructure. ${ }^{1}$

The port and maritime industry has recently evolved toward various forms of concentration and cooperation. The main types are: horizontal cooperation between shipping companies, horizontal cooperation between terminal operating companies (TOCs), and vertical cooperation between TOCs and shipping companies (see e.g. Heaver et al., 2001). As a consequence of port reform, and over the last couple of decades there has been a decrease in the number of state-owned terminal facilities. This process of port privatization has led to private investment in container terminals, as a means to overcome shortages in port infrastructures. ${ }^{2}$ Mega-vessels cannot be handled at all terminals, thus bringing about a significant increase in stevedoring costs, and the loading/unloading operations require more time. With a growing complexity in global transport networks, managing the factor time becomes crucial for current liner service design. Shorter waiting times and delays redound in benefits to customers that save on logistics costs (Notteboom, 2006). Specifically, Wilmsmeier et al (2006) find that port efficiency is the most determinant element, followed by port infrastructure, private

\footnotetext{
${ }^{1}$ We shall refer to open port facilities to mean that any shipping line can access them on equal conditions, regardless of the type of property, be them public or be them independently operated multi-user facilities.

${ }^{2}$ Midoro et al. (2005) survey the recent history of liner shipping and talk about one evolution (growth in vessel size and in ports) and three revolutions (containerisation, intermodal ship-rail transport, and transhipment). The current wave of the integration and globalization of the terminal business and liners is to be put in the transhipment revolution.
} 
sector participation and inter-port connectivity. Doubling port efficiency in a pair of ports involved in bilateral trade has the same impact on international transport costs as halving the distance between them. All these factors have driven liners to control a number of terminal facilities all over the world. Within the structural evolution in ports, many shipping lines have established their own terminal operating branch. To illustrate, the APMoller-Maersk group operates approximately 50 container terminals around the world. This certainly introduces an element of strategy in such vertical integration arrangements. In particular, a key decision for carriers is whether to manage a dedicated terminal (and thus keep it exclusive) or whether to have a terminal accessible to all users (thus keeping it non-exclusive). Indeed, most global carriers run their own terminals; others are shifting to common-user (non-exclusive) terminals, as done by Maersk creation of AP Moller Terminals and Japanese Yusin Kaisha. Of course, the shipping line can operate through any port terminal. ${ }^{3}$

The liner shipping market has a number of characteristics, of which the following stand out. First, it is an oligopolistic market: the top 20 carriers account for over $80 \%$ of vessel capacity. Second, mergers and cooperation agreements have been common in the past few years. Since the $90 \mathrm{~s}$, the formation of strategic alliances permits carriers to pool vessels on main commercial routes and profit from scope and network economies. Shipping companies now establish forms of vertical integration to get a tighter grip on logistics chains, in particular, as a means of gaining control over port capacity (Van de Voorde and Vanelslander, 2009). The emergence of dedicated container terminals over the last years may be due to the increasing gap between the objectives of ports and those of shipping lines. Haralambides et al. (2002) provide a detailed discussion and analysis of the costs and benefits of dedicated terminals. Third, organizing the transport of freight by sea involves a number of different agents: freight forwarders, port actors (cargo handlers, stevedores, and shipping agents), shipping companies and inland transport providers. Vertical integration can help companies run their business more efficiently. ${ }^{4}$ Fourth, in the strong competition environment that characterizes the industry, product differentiation (through a wider range of services offered) has a strong influence on performance (Panayides, 2003).

This paper develops an oligopoly model with vertical relations that accounts for the aforementioned characteristics of the maritime freight industry. The firms upstream are the ship-

\footnotetext{
${ }^{3}$ The importance of market power and the integration of activities in the maritime sector are made clear by two recent OECD works by Frémont (2009) and Van de Voorde and Vanelslander (2009).

${ }^{4}$ There are pure TOCs and also other forms of partnerships between shipping lines and stevedores (such as joint ventures, contracts, the creation of partially owned subsidiaries, and so on). See Soppé et al. (2009) for a recent review on reasons leading to the integration of vertical activities.
} 
ping lines that offer differentiated freight services and operate through the downstream open port facilities. Then one of the companies invests in a private terminal. This integration of services means it can secure its port operations, save on costs and better schedule its ships. Such substantial investment can be justified by a high volume of traffic with the objective of providing better service quality. That is to say, customers will be willing to pay higher fares for that traffic through the new liner terminal, mainly because of faster transit time. The terminal is in principle a dedicated terminal and the carrier investor decides whether to continue using the open port facilities. However, and for strategic reasons, such investment can be best paid off if the terminal is hired to other liners at some price. All these competition scenarios are considered and compared. Our setting thus focuses on shipping lines' decisions and not on port management. ${ }^{5}$ It allows us to examine the new business line adopted by major liners and to evaluate the opportunity of exclusive terminals. It is shown that the shipping line that invests in the new terminal finds it advantageous to operate its freight both through its own terminal and the open facilities. In this way it can segment the market and sort out those customers that are willing to pay more for a better service. In case the shipping line lets the rival use the private terminal in exchange for a fee, we find that the fare of the carrier investor is higher than the rival's at the open facilities, whereas the opposite happens at the liner terminal. With these fares the carrier investor pushes some of the rival's freight from the open to the new terminal. Our main finding is that the shipping line that builds its own terminal attains higher profits with a non-exclusive terminal than with a dedicated terminal; interestingly, the rival carrier also gets more profits under the non-exclusive regime. With the fee, the carrier investor partially internalizes the competition stemming from letting the rival offer a new product. Both shipping lines offer a wider variety of services, total freight increases and the resulting equilibrium fares exceed those under a dedicated terminal.

The paper is organized as follows. Section 2 provides some evidence on the recent trend regarding vertical integration in maritime freight. Then Section 3 presents the model and develops the various competition scenarios. The main results are presented and discussed. Section 4 concludes.

\footnotetext{
${ }^{5}$ Defilippi and Flor (2008) study the role of a regulatory framework on access and pricing for port infrastructures; they examine the effects on facilitating further private investment in developing countries.
} 


\section{The Involvement in Terminals by Shipping Lines}

As acknowledged in the Green Paper $\operatorname{COM}(97) 678$ on seaports and maritime infrastructures in the European Union, and the Communication from the Comission to the European parliament and the Council, COM 2001/0047, the financing of ports and policies on charging their users vary from one country to another, reflecting the considerable differences in the approach taken towards their ownership and organization. In Europe we find state-owned ports, others that are run by local governments and some that are in the hands of private management. The lack of transparency of port accounts as well as the extensive application of subsidies and public aids disguise final prices. To illustrate, Spain's Port System does not escape to this description. The port fares are regulated by the central government though companies offer discounts on final prices, which translates to significant dispersion of observed fares. The fact that ports tend to be seen as commercially oriented entities has driven the Spanish government to modify the Law on Ports. Although charges should follow average cost pricing or marginal cost pricing, there is still much to be done. Therefore, data on changes in market structures and volumes of freight can be useful indicators of the business strategies recently undertaken by global carriers.

Dedicated terminals are a widespread phenomena not only in Europe but also in Asia and North America. Drewry Shipping Consultants (2003) collected throughput figures for terminals in which carriers have a non-minority shareholding: Evergreen handled 5.7 million TEU worldwide on its terminals in 2002, Cosco 4.7 million TEU, Hanjin 4.7, APL 4.3, NYK Line 3.5 (including 1.3 million TEU at its subsidiary Ceres Terminals) OOCL 3, NOL 2.5, K-Line 2.2, MSC 2.2, Yang Ming 1.3 and Hyundai 1.1 million TEU. The strategy of holding dedicated and/or non-exclusive terminals becomes fundamental for these big players. Container shipping lines approach terminal management in a different way: they seek control over berths while other 'pure' terminal operating companies manage multi-user facilities. Some of these liner terminals offer stevedoring services to third carriers as well, thereby creating some hybrid form in between pure dedicated facilities and independently operated multi-user facilities (Notteboom 2006).

Table 1 gathers information on the interests that many of such big carriers in handling terminals in European ports. Although not a generalized observation, many ports have seen an increase in throughput following the opening of new terminals. Dedicated terminals have been granted recently to APM-Maersk in Rotterdam and to MSC in Antwerp. As already noted, some of them opt for supplying terminal services only to their own vessels (as happens with MSC in ports like Valencia, Antwerp or Napels). However, other companies allow other 
shipping lines to use their port terminals for a determined fee (as is the case of Cosco in ports like Singapore). Table 2 reports aggregate freight data for some European ports where terminals were recently created. For example, the ports of Zeebrugge and Le Havre have seen a notable increase since 2005 and 2006, after the opening of CMA-CGM and MSC terminals, respectively. ${ }^{6}$

[Insert Tables 1 and 2 about here]

Furthermore, carrier investors continue using the open port facilities. As shall be seen below, this is a strategic feature supported by our model. In this regard, Table 3 shows some evidence about the structure and freight volumes in the port of Valencia. Up until the end of 2006 there was one main open container terminal, whose management has recently been conceded to a private operator. Since 2007 a new container terminal started to operate. It was built by the shipping line MSC, and it is a dedicated terminal for the operations of MSC although MSC operates part of its operations through the open terminal. The data of TEUs moved in both terminals are shown below.

[Insert Table 3 about here]

\section{The Model and Results}

We are interested in establishing whether a vertically integrated company prefers to keep a dedicated terminal (and continue employing the open facilities) or to let it to a rival liner. To this end we will compare prices, demand and profits under several scenarios.

\section{i) Benchmark scenario.}

Consider one (sea) port in which two shipping lines offer differentiated freight services. ${ }^{7}$ The demand system for transport is linear in the following form:

$$
\begin{aligned}
& Q_{A O}=a-f_{A O}+d f_{B O} \\
& Q_{B O}=a-f_{B O}+d f_{A O},
\end{aligned}
$$

where $Q_{i}$ represents the demand (expressed in TEU) and $f_{i}$ is the fare of shipping line $i$ $(i=A O, B O)$ and is charged for the services of transporting a TEU between two points. This

\footnotetext{
${ }^{6}$ The theoretical model precisely incorporates this fact; the new terminal creates demand for new and improved services.

${ }^{7}$ Competition on routes is a major determinant of transport costs, and is closely related to the total trade volume. In 2006, one in six importer exporter pairs was served by a single liner service, and over half were served by three or fewer (Hummels et al., 2009).
} 
demand system has the property that lower fares are boosting transport services as the cost of the shipped product in the destination markets is lower. ${ }^{8}$ This effect is bounded by $a$. Thus, parameter $a$ corresponds with the maximum level of transport demand for either shipping line in the departing situation. All of the freight is operated through the open terminal (subscripted by $O$ ). See Figure 1a. Parameter $d$ is related with the degree of product differentiation between the services supplied by shipping lines. It ranges from 0 to 1 , and services are less differentiated as $d$ approaches 1 . This (inverse) demand schedule captures horizontal product differentiation (parameter $d$ ) between the freight services, as well as vertical product differentiation regarding the quality of the services offered (parameter $a$ ). ${ }^{9}$ Shipping lines incur constant marginal costs of production $c$. In addition, they are charged $c u$ per TEU for terminal port use. ${ }^{10}$ We can therefore state the profit maximization problem for the shipping lines as follows:

$$
\begin{aligned}
\max _{f_{A O}} \pi_{A} & =\left(f_{A O}-c-c u\right) Q_{A O} \\
\max _{f_{B O}} \pi_{B} & =\left(f_{B O}-c-c u\right) Q_{B O} .
\end{aligned}
$$

This is a standard differentiated duopoly with a symmetric equilibrium characterized by:

$$
f_{A O}^{*}=f_{B O}^{*}=\frac{a+c+c u}{2-d},
$$

that leads to equilibrium demands and profits given by:

$$
Q_{A O}^{*}=Q_{B O}^{*}=\frac{a-(1-d)(c+c u)}{2-d} ; \pi_{A}^{*}=\pi_{B}^{*}=\left(\frac{a-(1-d)(c+c u)}{2-d}\right)^{2} .
$$

Note that we need to assume that $a>(1-d)(c+c u)$ in order to get positive equilibrium demands. However, this is a consistency assumption as it simply implies that the maximum willingness to pay for the transport service must be greater than the marginal costs of providing the service. ${ }^{11}$ One of the shipping lines, say $A$, sets up its own terminal at the port, which

\footnotetext{
${ }^{8}$ At the aggregate level Korinek and Sourding (2009) show that a doubling in bilateral maritime transport
} costs (expressed in $\$$ /tonne of goods shipped) is associated with between 66 and 80 percent decline in the value of imports between two given countries, holding constant the effects of GDP, distance and all other determinants of imports.

${ }^{9}$ That is, when both products are sold at the same price the high quality one has higher demand than the other. If we invert the above linear demand system the actual intercept is interpreted as the maximum willingness to pay for that good. Note that a higher $a$ implies a higher willingness to pay.

${ }^{10}$ Note that increasing returns to scale would make the modeling much more difficult without adding too much to the analysis. The reason is that we focus on symmetric shipping lines, thus economies of scale will affect both liners in a symmetric way and will imply more traffic for both carriers in the benchmark case.

${ }^{11}$ By inverting the linear demand system we obtain the maximum willingness to pay, which reads $\frac{a}{1-d}$ and it must be greater than $c+c u$. 
entails some fixed cost $F$. This decision will allow the shipping line to supply a better service quality (e.g., faster transit time and better management of the cargo). This is modelled as a change in the maximum demand parameter. Besides, the shipping line can still make use of the open port services or not. Further assume that there is no congestion at the port. ${ }^{12}$ These situations are analyzed next.

\section{ii) Dedicated use of the liner port terminal.}

\section{Pure use.}

In the case of a purely exclusive terminal, we assume that shipping line $A$ operates all its freight through its terminal, whereas shipping line $B$ only operates through the open terminal. See Figure 1b. The (asymmetric) demand system is now given by:

$$
\begin{aligned}
& Q_{A T}=\bar{a}-f_{A T}+d f_{B O} \\
& Q_{B O}=a-f_{B O}+d f_{A T},
\end{aligned}
$$

where $Q_{A T}$ denotes freight services of shipping line $A$ through the private terminal (subscripted by $T$ ); and $Q_{B O}$ (as above) corresponds to freight services of shipping line $B$ through the open terminal. As noted above, the improvement in service provided translates to the demand parameter $\bar{a}$, with $\bar{a}>a$. Shipping line $A$ now saves on unit costs $c u$ since its freight transport is operated via its own terminal. ${ }^{13}$ Therefore, the profit maximization problem faced by the shipping lines is stated as follows:

$$
\begin{aligned}
\max _{f_{A T}, f_{A O}} \pi_{A} & =\left(f_{A T}-c\right) Q_{A T}-F \\
\max _{f_{B O}} \pi_{B} & =\left(f_{B O}-c-c u\right) Q_{B O} .
\end{aligned}
$$

Solving the system formed by $\partial \pi_{A} / \partial f_{A T}=0$, and $\partial \pi_{B} / \partial f_{B O}=0$ leads to equilibrium fares:

$$
\begin{aligned}
f_{A T}^{p e} & =\frac{2(\bar{a}+c)+(a+c+c u) d}{4-d^{2}} \\
f_{B O}^{p e} & =\frac{d(\bar{a}+c)+2(a+c+c u)}{4-d^{2}}
\end{aligned}
$$

\footnotetext{
${ }^{12}$ De Borger et al. (2008) study the relevance of congestion when ports, which serve a hinterland, compete for traffic. Their analysis highlights that, under some circumstances, investments in port capacity can be welfare detrimental.

${ }^{13}$ We normalize the liner terminal's marginal operating cost to zero for the sake of exposition. We are just assuming that there is a cost advantage in the new terminal. Therefore, $c u$ is interpreted as the difference in operating costs once that of the new terminal is assumed to be zero.
} 
where superscript $p e$ stands for purely exclusive. Let $Q_{A T}^{p e}, Q_{B O}^{p e}, \pi_{A}^{p e}$ and $\pi_{B}^{p e}$ denote the equilibrium outputs and profits. It follows that, as long as $\bar{a}>a+c u, f_{A T}^{p e}>f_{B O}^{p e}, Q_{A T}^{p e}>Q_{B O}^{p e}$, and $\pi_{A}^{p e}>\pi_{B}^{p e}$ (abstracting from the fixed cost $F$ ). The condition on $\bar{a}$ is just meshing the two opposite effects on the shipping line $A^{\prime} s$ fares derived from the new terminal use. An increase in the service quality that entails an equilibrium fare rise, but also a decrease in marginal cost, since $c u$ is saved, that implies a decrease in the fare. ${ }^{14}$ The condition informs that only when $\bar{a}$ is high enough will the final effect be an increase in fares. Interestingly, it also implies that equilibrium fares are higher than in the benchmark scenario.

\section{Mixed use.}

In this case, both shipping lines employ the open facility whereas shipping line $A$ employs the private port terminal on an exclusivity basis. See Figure 1c. Thus, three different freight services are available depending on the shipping line and the type of terminal used. The (asymmetric) demand system is now given by:

$$
\begin{aligned}
& Q_{A T}=\bar{a}-f_{A T}+d\left(f_{A O}+f_{B O}\right) \\
& Q_{A O}=a-f_{A O}+d\left(f_{A T}+f_{B O}\right) \\
& Q_{B O}=a-f_{B O}+d\left(f_{A T}+f_{A O}\right),
\end{aligned}
$$

where $Q_{A O}$ denotes freight services of shipping line $A$ through the open terminal. Parameter $d$ now ranges from 0 to 0.5 , to have that an equal decrease in all the fares implies an increase in demand. Now the profit maximization problem faced by the shipping lines is stated as follows: ${ }^{15}$

$$
\begin{aligned}
\max _{f_{A T}, f_{A O}} \pi_{A} & =\left(f_{A T}-c\right) Q_{A T}+\left(f_{A O}-c-c u\right) Q_{A O}-F \\
\max _{f_{B O}} \pi_{B} & =\left(f_{B O}-c-c u\right) Q_{B O} .
\end{aligned}
$$

Solving the system formed by $\partial \pi_{A} / \partial f_{A T}=0, \partial \pi_{A} / \partial f_{A O}=0$ and $\partial \pi_{B} / \partial f_{B O}=0$ leads to

\footnotetext{
${ }^{14}$ Regarding shipping line $B^{\prime} s$ fare, the increase is due to strategic complementarity since $B^{\prime} s$ marginal profits are increasing with its rival's fare.

${ }^{15}$ We are not considering economies of scope in order to keep the model as simple as possible. Economies of scope would imply higher shipping line $A^{\prime} s$ profitability. Thus by assuming them away we are underestimating the positive effect of a new service in the market.
} 
equilibrium fares: ${ }^{16}$

$$
\begin{aligned}
f_{A T}^{e} & =\frac{(\bar{a}+c)\left(4-d^{2}\right)+3(a+c+c u) d(2+d)-d\left(4 c(1+d)+c u\left(4-d^{2}\right)\right)}{4\left(2-(3+d) d^{2}\right)} \\
f_{A O}^{e} & =\frac{(a+c+c u)(4+d(2+d))+(\bar{a}+c) d(4+d)-d(4 c(1+d)+c u(4+d) d)}{4\left(2-(3+d) d^{2}\right)} \\
f_{B O}^{e} & =\frac{\left.(2-d)(a+c+c u)+d(\bar{a}+c)-d^{2}(2 c+c u)\right)}{2(2-d(2+d))}
\end{aligned}
$$

where superscript $e$ stands for exclusivity. It can also be checked that the fares are increasing with $a$ and $\bar{a}$, and also with $c$ and $c u$ as long as $d \in(0,0.5)$.

Given these equilibrium fares, the equilibrium demands and profits can be obtained. Let $Q_{A T}^{e}, Q_{A O}^{e}, Q_{B O}^{e}, \pi_{A}^{e}$ and $\pi_{B}^{e}$ denote these expressions. It happens that $f_{A T}^{e}>f_{A O}^{e}$ and $Q_{A T}^{e}$ $>Q_{A O}^{e}$ if and only if $\bar{a}>a+c u(1+d)$, and the same condition is sufficient for $f_{A O}^{e}>f_{B O}^{e}$ and $Q_{A O}^{e}>Q_{B O}^{e}$. In fact it is easily proven that $f_{B O}^{e}$ grows with respect to the fare in the benchmark situation; the same happens for quantities. This is explained by the fact that more variety in services is attracting demand to the market in such a way that there is always demand for the new services. ${ }^{17}$

The comparison of the pure and the mixed scenarios yields the next result: ${ }^{18}$

Result 1 The shipping line A that builds the terminal is better off if it operates its freight through both terminals, i.e. $\pi_{A}^{e}>\pi_{A}^{p e}$.

Therefore, the owner of a new terminal will not exit the open terminal. In doing so, it can establish a sort of market segmentation device as one of its services is aimed at those customers that are willing to pay more for better service quality, while by offering the other service via the open terminal it is fighting for customers that would otherwise be patronized by shipping line $B$.

\footnotetext{
${ }^{16}$ The fulfilment of the second order conditions for a maximum require that $4\left(-2+(3+d) d^{2}\right)<0$, which holds for values of $d \in(0,0.732)$.

${ }^{17}$ This is a feature clearly embedded in the representative consumer approach to product differentiation that we are considering. The introduction of a new product has always a market expansion effect than outweighs the effect of more products in the market. The convenience of this approach rather than any other is an empirical issue. That is, whether the considered market has a high potential growth or is a mature and stabilized market. We are focusing on the former situation.

${ }^{18}$ The proof proceeds as follows. We first prove that $\Delta_{A}^{e-p e}(\bar{a}, a, c u, c) \equiv \pi_{A}^{e}-\pi_{A}^{p e}$, is increasing in $\bar{a}$ at an increasing rate. Therefore, $\Delta_{A}^{e-p e}(\bar{a}, a, c u, c)>\Delta_{A}^{e-p e}(\bar{a}=a, a, c u, c)$. We then check that indeed $\Delta_{A}^{e-p e}(\bar{a}=$ $a, a, c u, c)>0$ for all $d<\frac{1}{2}$.
} 


\section{iii) Non-exclusive use of the liner port terminal.}

Both shipping lines employ the public and the new facilities (see Figure 1d)., which means that there are four differentiated products as gathered by the (asymmetric) demand system:

$$
\begin{aligned}
& Q_{A T}=\bar{a}-f_{A T}+d\left(f_{A O}+f_{B T}+f_{B O}\right) \\
& Q_{A O}=a-f_{A O}+d\left(f_{A T}+f_{B T}+f_{B O}\right) \\
& Q_{B T}=\bar{a}-f_{B T}+d\left(f_{A T}+f_{A O}+f_{B O}\right) \\
& Q_{B O}=a-f_{B O}+d\left(f_{A T}+f_{A O}+f_{B T}\right) .
\end{aligned}
$$

Note that now shipping line $A$ extracts revenue from the rival shipping line by charging a per unit fare of $t$ on $B^{\prime} s$ freight through the private terminal, $Q_{B T}$. This means that shipping line $A$ is behaving as a service provider for shipping line $B$ thus entering into a vertical relationship. Further note that parameter $d$ ranges from 0 to $1 / 3$. This results in the following profit maximization problem:

$$
\begin{aligned}
\max _{f_{A T}, f_{A O}} \pi_{A} & =\left(f_{A T}-c\right) Q_{A T}+\left(f_{A O}-c-c u\right) Q_{A O}+t Q_{B T}-F \\
\max _{f_{B T}, f_{B O}} \pi_{B} & =\left(f_{B T}-c-t\right) Q_{B T}+\left(f_{B O}-c-c u\right) Q_{B O} .
\end{aligned}
$$

Solving the system formed by $\partial \pi_{A} / \partial f_{A T}=0, \partial \pi_{A} / \partial f_{A O}=0, \partial \pi_{B} / \partial f_{B T}=0$ and $\partial \pi_{B} / \partial f_{B O}=$ 0 leads to equilibrium fares: ${ }^{19}$

$$
\begin{aligned}
f_{A T}^{n e} & =\frac{(2-d)(\bar{a}+c)+3 d(a+c+c u)-d(2-d) c u-2 d(1+d) c+3 d\left(1-d^{2}\right) t}{4(1+d)(1-2 d)} \\
f_{A O}^{n e} & =\frac{(2-d)(a+c+c u)+3 d(\bar{a}+c)-3 d^{2} c u-2 d(1+d) c+3 d\left(1-d^{2}\right) t}{4(1+d)(1-2 d)} \\
f_{B T}^{n e} & =\frac{(2-d)(\bar{a}+c)+3 d(a+c+c u)-d(2-d) c u-2 d(1+d) c+(1+d)\left(2-4 d+3 d^{2}\right) t}{4(1+d)(1-2 d)} \\
f_{B O}^{n e} & =\frac{(2-d)(a+c+c u)+3 d(\bar{a}+c)-3 d^{2} c u-2 d(1+d) c+3 d(1+d) t}{4(1+d)(1-2 d)} .
\end{aligned}
$$

Again, it is straightforward to see that the fares are increasing with $a$ and $\bar{a}$, with $c$ and $c u$ as long as $d \in(0,1 / 3)$; these costs enter symmetrically in all the expressions. The unit fare $t$ affects positively and in the same magnitude the fares for shipping line $A$. Besides, $f_{B T}^{n e}>f_{A T}^{n e}$ and $f_{A O}^{n e}>f_{B O}^{n e}$, i.e., the fare of freight through the liner terminal is higher for shipping line $B$, whereas the fare of freight through the usual facilities is higher for shipping line $A$. It is interesting to note that those fare differences arise as long as $t>0$. When $t$ is zero, freight

\footnotetext{
${ }^{19}$ The fulfilment of the second order conditions for a maximum require that $16-48 d^{2}-32 d^{3}>0$, which holds for values of $d \in(0,0.5)$.
} 
services at the same terminal have the same equilibrium fares. The fares at the new terminal exceed those at the open terminal if and only if $\bar{a}>a+(1+d) c u$. Besides as services become more differentiated, i.e. lower $d$, the fare difference in the liner terminal increases, while that difference at the open terminal decreases. Regarding the pricing policy within a shipping line, it always happens that the high quality service is priced higher that the low quality one if $\bar{a}$ is big enough and regardless of the per unit fare on $B^{\prime} s$ freight via the new terminal. The next result summarizes our findings:

Result 2 i) Within the private terminal we have that $f_{B T}^{n e}>f_{A T}^{n e}$ whereas within the open terminal $f_{A O}^{n e}>f_{B O}^{n e}$.

ii) Shipping line $A$ sets fares such that $f_{A T}^{n e}>f_{A O}^{n e}$ whereas for shipping line $B, f_{B T}^{n e}>f_{B O}^{n e}$ as long as $\bar{a}>a+(1+d) c u$.

The equilibrium fares are substituted back in the profit function $\pi_{A}$ to obtain the per unit fare $t$ that shipping line $A$ charges shipping line $B$ for the use of its terminal. Setting $\partial \pi_{A} / \partial t$ equal to zero and solving for $t$ yields: ${ }^{20}$

$$
t^{n e}=\frac{\bar{a}\left(2-6 d+4 d^{2}+3 d^{3}\right)+a d\left(2-4 d+3 d^{2}\right)-2 c(1+d)(1-3 d)\left(1-3 d+3 d^{2}\right)+c u d\left(11-6 d+d^{2}\right)}{(1+d)(2-3 d)(2-d(7+3 d(-2+d))}
$$

where it is easily checked that $t^{n e}>c u .^{21}$ Regarding freight services the following ranking is established $Q_{A T}^{n e}>Q_{B T}^{n e}>Q_{B O}^{n e}>Q_{A O}^{n e}$. This happens for all possible $t>0$, where i) $Q_{A T}^{n e}>Q_{B T}^{n e}$ since $f_{B T}^{n e}>f_{A T}^{n e}$, ii) $Q_{B O}^{n e}>Q_{A O}^{n e}$ since $f_{A O}^{n e}>f_{B O}^{n e}$. Finally $Q_{B T}^{n e}>Q_{B O}^{n e}$ if and only if $\bar{a}>a+(1+d)\left(t^{n e}-c u\right)$ since $t^{n e}>c u$. Finally, $Q_{B T}^{n e}>Q_{A O}^{n e}$ if and only if

$$
\bar{a}>a+(1+d)\left(t^{n e}-c u\right)-3 d(1+d) t^{n e} \text {. }
$$

We may now compare whether shipping line $A$ finds it strategically advantageous to have a privately built terminal on a non-exclusive regime. The next result summarizes the main finding in our paper. ${ }^{22}$

\footnotetext{
${ }^{20}$ The fulfilment of the second order condition requires that $d \in(0,0.39)$.

${ }^{21}$ We first use the fact that the difference $t^{n e}-c u$ is increasing in $\bar{a}$. Then, we use the conditions $\bar{a}>$ $a+(1+d) c u, a>c+c u$, and $d<\frac{1}{3}$ to obtain the result.

${ }^{22}$ Fares rankings are obtained directly just using that $d<1 / 3$ and $\bar{a}>a$. In order to prove part $i$ ) we first prove that $\Delta_{A}^{n e-e}(\bar{a}, a, c u, c) \equiv \pi_{A}^{n e}-\pi_{A}^{e}$, is increasing in $\bar{a}$ at an increasing rate. Therefore, $\Delta_{A}^{n e-e}(\bar{a}, a, c u, c)>$ $\Delta_{A}^{n e-e}(\bar{a}=a, a, c u, c)$. Finally we prove that $\Delta_{A}^{n e-e}(\bar{a}=a, a, c u, c)>0$ for all $d<\frac{1}{3}$. Similarly for $\left.i i\right)$, define $\Delta_{B}^{n e-e}(\bar{a}, a, c u, c) \equiv \pi_{B}^{n e}-\pi_{B}^{e}$, which is also increasing in $\bar{a}$ at an increasing rate, therefore $\Delta_{B}^{n e-e}(\bar{a}, a, c u, c)>$ $\Delta_{B}^{n e-e}(\bar{a}=a, a, c u, c)$. We next prove that $\Delta_{B}^{n e-e}(\bar{a}=a, a, c u, c)$ is increasing in $a$, so $\Delta_{B}^{n e-e}(\bar{a}=a, a, c u, c)>$ $\Delta_{B}^{n e-e}(c u, c u, c u, c)$. Finally, we prove that $\Delta_{B}^{n e-e}(c u, c u, c u, c)>0$ for any $d<\frac{1}{3}$.
} 
Result 3 Regardless of the value $\bar{a}$ and for $d \in\left(0, \frac{1}{3}\right)$,

i) Shipping line $A$ is better off with a non-exclusive terminal, i.e. $\pi_{A}^{n e}>\pi_{A}^{e}$,

ii) Shipping line $B$ is also better off with a non-exclusive terminal, i.e. $\pi_{B}^{n e}>\pi_{B}^{e}$

iii) The fares are higher under a non-exclusive regime, i.e. $f_{A T}^{n e}>f_{A T}^{e}, f_{A O}^{n e}>f_{A O}^{e}$ and $f_{B O}^{n e}>f_{B O}^{e}$.

The intuition of the result is as follows. As previously explained more variety in the market implies higher demand: the increase in port facilities makes this spot attractive for customers. This is beneficial for both shipping lines. Thus, shipping line $B$ is better off since it now is providing two differentiated services. For shipping line $A$ the reason is different; by letting the rival use the new terminal, shipping line $A$ is better off since it is getting a share of the profits coming from the new product. In fact, shipping line $A$ has the upper hand in the market since by choosing the rate $t$, which is a marginal cost for shipping liner $B$, is able to partially internalize the competition it suffers from the new product. Furthermore and since equilibrium fares are increasing in $t$, a higher $t$ helps sustain higher prices in the market which raises the profitability of shipping line $A^{\prime} s$ products.

\section{Conclusions}

Top shipping lines have aimed at reducing their production costs, diversifying their investments and achieving paths of vertical integration along the transportation chain (Panayides and Cullinane, 2002). This paper has considered a private investment in a container terminal to examine i) whether it is strategically profitable for a shipping line to integrate services in the logistic chain while still routing cargo through the open port facilities, and ii) whether to keep a dedicated or a non-exclusive terminal.

An important concern for policy-makers and researchers in the maritime industry has to do with identifying factors explaining differences in shipping rates (see Korinek and Sourding, 2009). What our analysis highlights is that factors, such as market structure, port services and infrastructures can be useful in better understanding the existing differences among shipping costs across ports. By comparing several competition regimes, we have shown that, firstly, a shipping line with a dedicated terminal will be interested in deviating part of its traffic through the open terminal. Secondly, it will be also find it profitable to supply its terminal services to other shipping lines. In this case, more differentiated products are offered, and production will be maximal in the non-exclusivity case. In terms of policy implications this is an interesting result because the non exclusive use of the liner terminal enhances social welfare 
- liners' profits are higher and so is total freight. Strategically, the liner that invests in a new terminal, optimally chooses fares in such a way that part of the rival's traffic is diverted from the open terminal: a higher share of better freight service is provided, total freight increases and fares are higher.

The paper can be extended in a number of directions. The sea transport chain between an origin and destination via two ports involves a land leg and a sea leg, in addition to port transit, on which we have focused. Thus it might be worth studying the convenience of integrating further activities; hinterland access conditions can be a fundamental element in the modeling of port competition (Zhang, 2008). Further research should address the interaction of maritime transport with competing modes of transport to more faithfully assess the convenience of certain strategies and policies.

\section{References}

[1] $\operatorname{COM}(97)$ 678, Green Paper on Seaports and Maritime Infrastructure.

[2] De Borger, B., S. Proost and K. Van Dender (2008), "Private Port Pricing and Public Investment in Port and Hinterland Capacity", Journal of Transport Economics and Policy, 42(3), 527-561.

[3] Defilippi, E. and L. Flor (2008), "Regulation in a Context of Limited Competition: A Port Case", Transportation Research Part A, 42, 762-773.

[4] Drewry Shipping Consultants (2003), "Annual Review of Global Container Terminal Operators", Drewry Shipping Consultants: London.

[5] Frémont, A., (2009), "Empirical Evidence for Integration and Disintegration of Maritime Shipping, Port and Logistics Activities", OECD/ITF Discussion paper 2009-1.

[6] Haralambides, H., P. Cariou and M. Benacchio (2002), "Costs, benefits and Pricing of Dedicated Container Terminals", International Journal of Maritime Economics, 4, 21-34.

[7] Heaver, T., H. Meersman and E. Van de Voorde (2001), "Cooperation and Competition in International Container Transport: Strategies for Ports", Maritime Policy and Management, 25, 3, 293-306. 
[8] Hummels, D., V. Lugovskyy and A. Skiba (2009), "The Trade Reducing Effects of Market Power in International Shipping", Journal of Development Economics, 89, 84-97.

[9] Korinek, J. and P. Sourding (2009), "Maritime Transport Costs and their Impact on Trade", OECD working paper TAD/TC/WP-2009-7.

[10] Midoro, R., E. Musso and F. Parola (2005), "Maritime Liner Shipping and the Stevedoring Industry: Market Structure and Competition Strategies", Maritime Policy and Management, 32,2, 89-106.

[11] Notteboom, T. (2006), "The Time Factor in Liner Shipping Services", Maritime Economics and Logistics, 8, 19-39.

[12] Panayides, P. and K. Cullinane (2002), "Competitive Advantage in Liner Shipping: A Review and Research Agenda", International Journal of Maritime Economics, 4, 189209.

[13] Panayides, P. (2003), "Competitive strategies and organizational performance in ship management", Maritime Policy and Management, 30, 2, 123-140.

[14] Soppé, M., F. Parola and A. Frémont (2009), "Emerging Inter-industry Partnerships between Shipping Lines and Stevedores: From Rivalry to Cooperation?", Journal of Transport Geography, 17, 10-20.

[15] Suykens, F. and E. Van de Voorde (1998), "A Quarter of a Century of Port Management in Europe: Objectives and Tools", Maritime Policy and Management, 25, 3, 251-261.

[16] Van de Voorde, E. And Vanelslander, T. (2009), "Market Power and Vertical and Horizontal Integration in the Maritime Shipping and Port Industry", OECD/ITF discussion paper 2009-2.

[17] Wilmsmeier, G., J. Hoffmann and R. Sánchez (2006), "The Impact of Port Characteristics on International Maritime Transport Costs", in Port Economics, Research in Transportation Economics, vol. 16, K. Cullinane and W. Talley, eds., Elsevier.

[18] Zhang, A. (2008), "The Impact of Hinterland Access Conditions on Rivalry between Ports", OECD/ITF discussion paper 2008-8. 


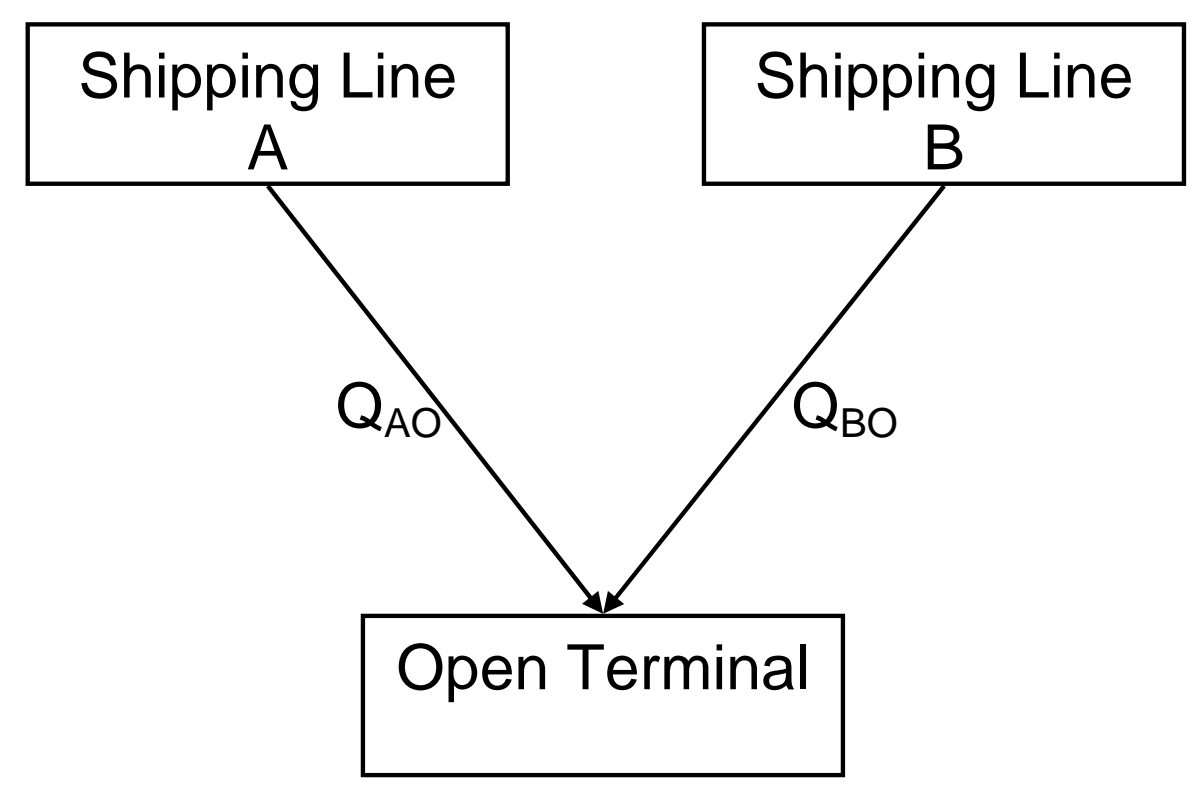

Figure 1a (Benchmark)
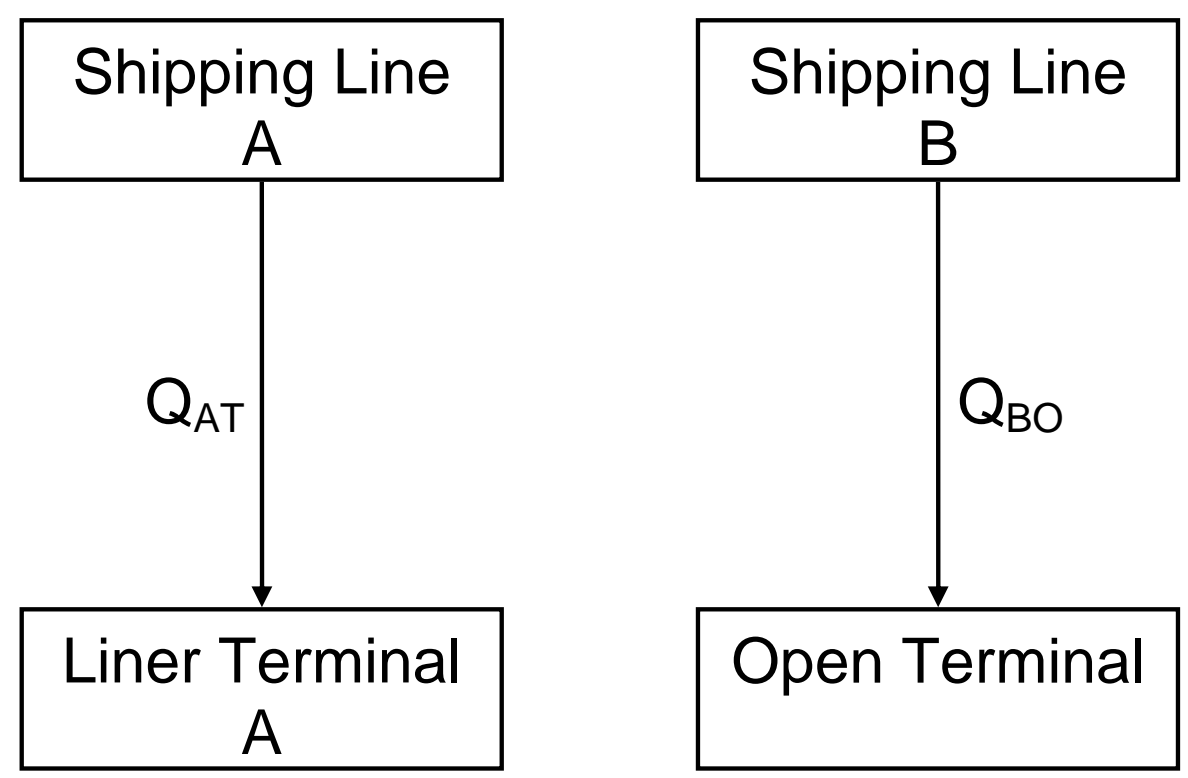

Figure $1 b$. Pure use of the dedicated liner terminal 


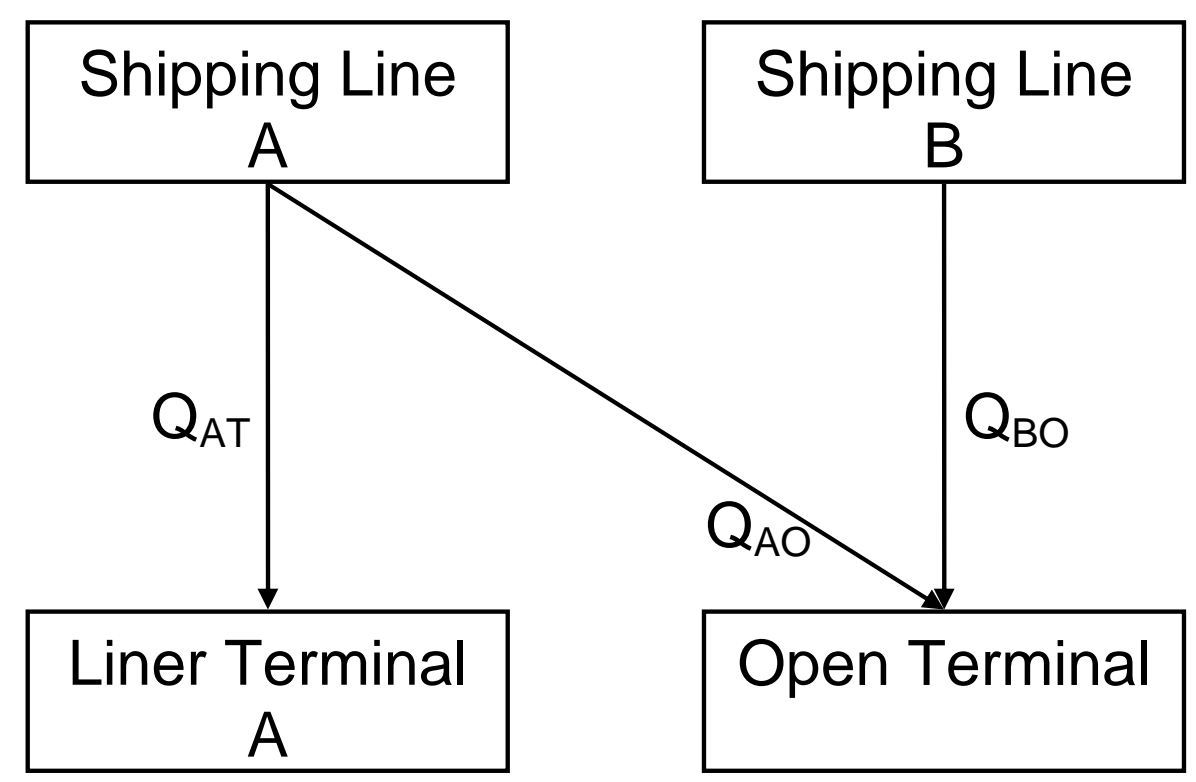

Figure 1c. Mixed use of the dedicated liner terminal

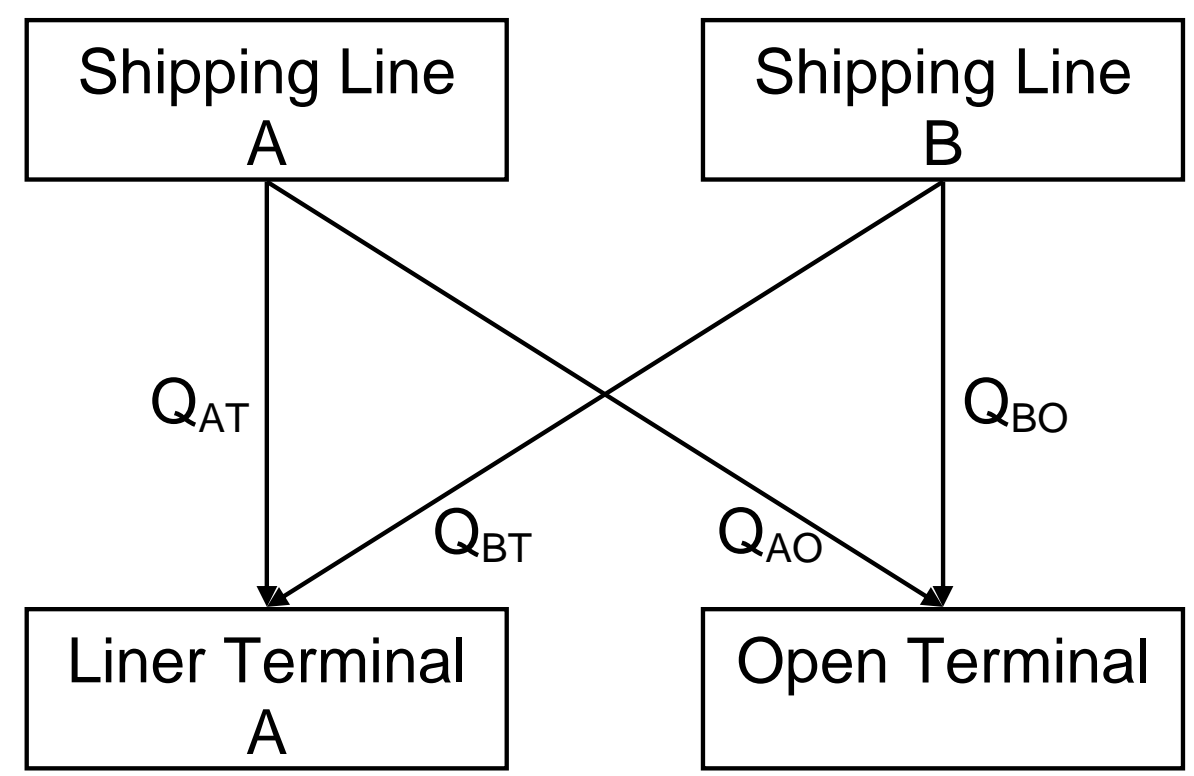

Figure 1d. Non exclusive use of the liner terminal 


\begin{tabular}{|l|l|l|}
\hline \multicolumn{2}{|c|}{ Table 1 } \\
Some examples of shipping lines' direct interest in European terminals
\end{tabular}

\begin{tabular}{|l|c|c|r|r|r|r|r|}
\hline \multicolumn{7}{|c|}{ Table 2} \\
\hline & 2002 & 2003 & 2004 & 2005 & 2006 & 2007 & \multicolumn{1}{c|}{2008} \\
\hline Algeciras & 2,234 & 2,516 & 2,937 & 3,179 & 3,257 & 3,421 & 3,328 \\
\hline Antwerp & 4,777 & 5,445 & 6,064 & 6,482 & 7,019 & 8,176 & 8,663 \\
\hline Le Havre & 1,720 & 1,977 & 2,145 & 2,118 & 2,138 & 2,656 & 2,500 \\
\hline Malta & & & 1,460 & 1,321 & 1,458 & 1,887 & 2,260 \\
\hline Rotterdam & 6,515 & 7,107 & 8,281 & 9,287 & 9,655 & 10,791 & 10,784 \\
\hline Zeebruge & 958 & 1,012 & 1,196 & 1,407 & 1,653 & 2,020 & 2,209 \\
\hline Source: own elaboration.
\end{tabular}

\begin{tabular}{|l|c|c|c|r|r|}
\hline \multicolumn{7}{|c|}{ Table3 } \\
Number of TEUs moved in the port of Valencia through open and MSC terminals \\
\hline & 2004 & 2005 & 2006 & 2007 & \multicolumn{1}{c|}{2008} \\
\hline Open Terminal & $1,510,431$ & $1,674,955$ & $1,851,740$ & $1,571,957$ & $1,579,740$ \\
\hline Terminal MSC & & & & 515,784 & 875,946 \\
\hline MSC through open & & & & 171,928 & 323,980 \\
\hline Total & $1,510,431$ & $1,674,955$ & $1,851,740$ & $2,259,669$ & $2,779,666$ \\
\hline Source: own elaboration & & & & \\
\hline
\end{tabular}




\section{Recent titles \\ CORE Discussion Papers}

2010/63. Marco DI SUMMA and Laurence A. WOLSEY. Mixing sets linked by bidirected paths.

2010/64. Kaz MIYAGIWA, Huasheng SONG and Hylke VANDENBUSSCHE. Innovation, antidumping and retaliation.

2010/65. Thierry BRECHET, Natali HRITONENKO and Yuri YATSENKO. Adaptation and mitigation in long-term climate policies.

2010/66. Marc FLEURBAEY, Marie-Louise LEROUX and Gregory PONTHIERE. Compensating the dead? Yes we can!

2010/67. Philippe CHEVALIER, Jean-Christophe VAN DEN SCHRIECK and Ying WEI. Measuring the variability in supply chains with the peakedness.

2010/68. Mathieu VAN VYVE. Fixed-charge transportation on a path: optimization, LP formulations and separation.

2010/69. Roland Iwan LUTTENS. Lower bounds rule!

2010/70. Fred SCHROYEN and Adekola OYENUGA. Optimal pricing and capacity choice for a public service under risk of interruption.

2010/71. Carlotta BALESTRA, Thierry BRECHET and Stéphane LAMBRECHT. Property rights with biological spillovers: when Hardin meets Meade.

2010/72. Olivier GERGAUD and Victor GINSBURGH. Success: talent, intelligence or beauty?

2010/73. Jean GABSZEWICZ, Victor GINSBURGH, Didier LAUSSEL and Shlomo WEBER. Foreign languages' acquisition: self learning and linguistic schools.

2010/74. Cédric CEULEMANS, Victor GINSBURGH and Patrick LEGROS. Rock and roll bands, (in) complete contracts and creativity.

2010/75. Nicolas GILLIS and François GLINEUR. Low-rank matrix approximation with weights or missing data is NP-hard.

2010/76. Ana MAULEON, Vincent VANNETELBOSCH and Cecilia VERGARI. Unions' relative concerns and strikes in wage bargaining.

2010/77. Ana MAULEON, Vincent VANNETELBOSCH and Cecilia VERGARI. Bargaining and delay in patent licensing.

2010/78. Jean J. GABSZEWICZ and Ornella TAROLA. Product innovation and market acquisition of firms.

2010/79. Michel LE BRETON, Juan D. MORENO-TERNERO, Alexei SAVVATEEV and Shlomo WEBER. Stability and fairness in models with a multiple membership.

2010/80. Juan D. MORENO-TERNERO. Voting over piece-wise linear tax methods.

2010/81. Jean HINDRIKS, Marijn VERSCHELDE, Glenn RAYP and Koen SCHOORS. School tracking, social segregation and educational opportunity: evidence from Belgium.

2010/82. Jean HINDRIKS, Marijn VERSCHELDE, Glenn RAYP and Koen SCHOORS. School autonomy and educational performance: within-country evidence.

2010/83. Dunia LOPEZ-PINTADO. Influence networks.

2010/84. Per AGRELL and Axel GAUTIER. A theory of soft capture.

2010/85. Per AGRELL and Roman KASPERZEC. Dynamic joint investments in supply chains under information asymmetry.

2010/86. Thierry BRECHET and Pierre M. PICARD. The economics of airport noise: how to manage markets for noise licenses.

2010/87. Eve RAMAEKERS. Fair allocation of indivisible goods among two agents.

2011/1. Yu. NESTEROV. Random gradient-free minimization of convex functions.

2011/2. Olivier DEVOLDER, François GLINEUR and Yu. NESTEROV. First-order methods of smooth convex optimization with inexact oracle.

2011/3. Luc BAUWENS, Gary KOOP, Dimitris KOROBILIS and Jeroen V.K. ROMBOUTS. A comparison of forecasting procedures for macroeconomic series: the contribution of structural break models.

2011/4. Taoufik BOUEZMARNI and Sébastien VAN BELLEGEM. Nonparametric Beta kernel estimator for long memory time series. 


\section{Recent titles}

\section{CORE Discussion Papers - continued}

2011/5. Filippo L. CALCIANO. The complementarity foundations of industrial organization.

2011/6. Vincent BODART, Bertrand CANDELON and Jean-François CARPANTIER. Real exchanges rates in commodity producing countries: a reappraisal.

2011/7. Georg KIRCHSTEIGER, Marco MANTOVANI, Ana MAULEON and Vincent VANNETELBOSCH. Myopic or farsighted? An experiment on network formation.

2011/8. Florian MAYNERIS and Sandra PONCET. Export performance of Chinese domestic firms: the role of foreign export spillovers.

2011/9. Hiroshi UNO. Nested potentials and robust equilibria.

2011/10. Evgeny ZHELOBODKO, Sergey KOKOVIN, Mathieu PARENTI and Jacques-François THISSE. Monopolistic competition in general equilibrium: beyond the CES.

2011/11. Luc BAUWENS, Christian HAFNER and Diane PIERRET. Multivariate volatility modeling of electricity futures.

2011/12. Jacques-François THISSE. Geographical economics: a historical perspective.

2011/13. Luc BAUWENS, Arnaud DUFAYS and Jeroen V.K. ROMBOUTS. Marginal likelihood for Markov-switching and change-point GARCH models.

2011/14. Gilles GRANDJEAN. Risk-sharing networks and farsighted stability.

2011/15. Pedro CANTOS-SANCHEZ, Rafael MONER-COLONQUES, José J. SEMPERE-MONERRIS and Oscar ALVAREZ-SANJAIME. Vertical integration and exclusivities in maritime freight transport.

\section{Books}

J. GABSZEWICZ (ed.) (2006), La différenciation des produits. Paris, La découverte.

L. BAUWENS, W. POHLMEIER and D. VEREDAS (eds.) (2008), High frequency financial econometrics: recent developments. Heidelberg, Physica-Verlag.

P. VAN HENTENRYCKE and L. WOLSEY (eds.) (2007), Integration of AI and OR techniques in constraint programming for combinatorial optimization problems. Berlin, Springer.

P-P. COMBES, Th. MAYER and J-F. THISSE (eds.) (2008), Economic geography: the integration of regions and nations. Princeton, Princeton University Press.

J. HINDRIKS (ed.) (2008), Au-delà de Copernic: de la confusion au consensus ? Brussels, Academic and Scientific Publishers.

J-M. HURIOT and J-F. THISSE (eds) (2009), Economics of cities. Cambridge, Cambridge University Press.

P. BELLEFLAMME and M. PEITZ (eds) (2010), Industrial organization: markets and strategies. Cambridge University Press.

M. JUNGER, Th. LIEBLING, D. NADDEF, G. NEMHAUSER, W. PULLEYBLANK, G. REINELT, G. RINALDI and L. WOLSEY (eds) (2010), 50 years of integer programming, 1958-2008: from the early years to the state-of-the-art. Berlin Springer.

\section{CORE Lecture Series}

C. GOURIÉROUX and A. MONFORT (1995), Simulation Based Econometric Methods.

A. RUBINSTEIN (1996), Lectures on Modeling Bounded Rationality.

J. RENEGAR (1999), A Mathematical View of Interior-Point Methods in Convex Optimization.

B.D. BERNHEIM and M.D. WHINSTON (1999), Anticompetitive Exclusion and Foreclosure Through Vertical Agreements.

D. BIENSTOCK (2001), Potential function methods for approximately solving linear programming problems: theory and practice.

R. AMIR (2002), Supermodularity and complementarity in economics.

R. WEISMANTEL (2006), Lectures on mixed nonlinear programming. 